\title{
The use of specialisation indices to predict vulnerability of coral-feeding butterflyfishes to environmental change
}

Rebecca J. Lawton ${ }^{\mathrm{a}, \mathrm{d}}$, Morgan S. Pratchett ${ }^{\mathrm{a}}$, Michael L. Berumen ${ }^{\mathrm{b}, \mathrm{c}}$.

${ }^{a}$ ARC Centre of Excellence for Coral Reef Studies, James Cook University, Townsville QLD, 4811, Australia

${ }^{\mathrm{b}}$ Red Sea Research Center, King Abdullah University of Science and Technology, Thuwal 23955-6900, Kingdom of Saudi Arabia

${ }^{c}$ Biology Department, Woods Hole Oceanographic Institution, Woods Hole 02543, USA

${ }^{\mathrm{d}}$ Corresponding author: Rebecca J Lawton; Tel: +61 7 47816058; Fax: +61 7 47816722;

Email: Rebecca.Lawton@jcu.edu.au 


\section{Abstract}

2 In the absence of detailed assessments of extinction risk, ecological specialisation is often

3 used as a proxy of vulnerability to environmental disturbances and extinction risk. Numerous

4 indices can be used to estimate specialisation; however, the utility of these different indices to

5 predict vulnerability to future environmental change is unknown. Here we compare the

6 performance of specialisation indices using coral-feeding butterflyfishes as a model group.

7 Our aims were to (i) quantify the dietary preferences of 3 butterflyfish species across habitats

8 with differing levels of resource availability; (ii) investigate how estimates of dietary

9 specialisation vary with the use of different specialisation indices; (iii) determine which specialisation indices best inform predictions of vulnerability to environmental change; and

11 (iv) assess the utility of resource selection functions to inform predictions of vulnerability to

12 environmental change. The relative level of dietary specialisation estimated for all three

13 species varied when different specialisation indices were used, indicating that the choice of

14 index can have a considerable impact upon estimates of specialisation. Specialisation indices

15 that do not consider resource abundance may fail to distinguish species that primarily use

16 common resources from species that actively target resources disproportionately more than

17 they are available. Resource selection functions provided the greatest insights into the

18 potential response of species to changes in resource availability. Examination of resource

19 selection functions, in addition to specialisation indices, indicated that Chaetodon trifascialis

20 was the most specialised feeder, with highly conserved dietary preferences across all sites,

21 suggesting that this species is highly vulnerable to the impacts of climate-induced coral loss

22 on reefs. Our results indicate that vulnerability assessments based on some specialisation

23 indices may be misleading and the best estimates of dietary specialisation will be provided by

24 indices which incorporate resource availability measures, as well as assessing responses of 25 species to changes in resource availability. 
27 Keywords: Chaetodontidae, dietary specialisation, ecological versatility, extinction risk, resource selectivity.

\section{Introduction}

With limited funding and constrained resources, there is limited capacity to effectively protect

the increasing number of species at risk of extinction due to environmental change, habitat loss and other anthropogenic disturbances (James et al.1999; Bottrill et al. 2008).

Identification of species or populations that face the greatest risk of extinction is therefore necessary to prioritise conservation efforts. For many species, assessment of extinction risk or vulnerability to predicted environmental change is costly, time-consuming and often impractical. This has lead to widespread efforts to identify factors correlated with high extinction risk or vulnerability across a wide range of taxa (e.g. McKinney 1997; Purvis et al. 2000a) that can be used in the absence of detailed assessments to predict which species are likely to be most vulnerable to future environmental change (Purvis et al. 2000b; Dulvy, et al. 2003).

One factor often correlated with high extinction risk and vulnerability is ecological specialisation (McKinney 1997; Fisher and Owens 2004; Colles et al. 2009). Ecological specialists are thought to be more vulnerable to environmental changes and disproportionately affected by changes in resource availability compared to generalist counterparts. Studies across both terrestrial and aquatic organisms and a range of specialisation types support this prediction (e.g. nesting cavity specialisation: Aitken and Martin 2008; habitat specialisation: Kotze and O'Hara 2003; Munday 2004; Fisher et al. 2003; dietary specialisation: Charrette et al. 2006; Graham 2007; dietary and habitat specialisation: Harcourt et al. 2002) suggesting 
that in many cases ecological specialisation is a key driver of extinction risk. Thus, identifying species that are ecological specialists can provide a useful starting point to predict likely vulnerability and prioritise conservation actions. However, binary classifications of species as either specialists or generalists can mask interspecific variation in ecological versatility. This is of critical importance if specialisation is used as a vulnerability proxy as grouping specialists into a single category assumes equal vulnerability among all specialists, whereas recent research suggests that vulnerability increases with increasing specialisation (Pratchett et al. 2008). Furthermore, the use of different specialisation indices can result in different estimates of specialisation, even when the same data are considered (DeVictor et al. 2010). As biodiversity becomes increasingly threatened by the combined effects of climate change and anthropogenic disturbances (Chapin et al. 2000; Thomas et al. 2004), there is a need for greater focus on the way that specialisation is assessed and interpreted to estimate vulnerability.

A variety of approaches are used to quantify ecological specialisation. The most basic measures report the number of different resource categories which are used by a particular species or population and conclude that a species is specialised if they are only using resources from a few categories (e.g. Eeley and Foley 1999; Owens and Bennett 2000). More commonly, specialisation is quantified using niche breadth indices such as the Simpsons index or the Shannon-Wiener diversity index, which provide estimates of specialisation based on richness and evenness of resource use (e.g. Munday 2004; Christensen and Kleindorfer 2009). While these types of analyses provide very general information about the degree of specialisation, if resources are not equally available they can result in misleading estimates of specialisation as species using resources in proportion to their availability may appear to have narrower niches than more specialised species (Petraitis 1979). A number of studies have 
addressed this issue through the use of specialisation indices such as Smiths niche breadth measure or chi square log likelihood statistics that incorporate estimates of resource availability (e.g. Gardiner and Jones 2005; Pratchett 2007). An alternative approach to quantifying specialisation is to use measures of among-individual specialisation. In contrast to specialisation indices which determine the niche of the population as a whole, amongindividual specialisation indices provide information about how variation in resource use is spread between individuals within a population (e.g. Araujo and Gonzaga 2007; Araujo et al. 2008). These metrics compare the niche size of individuals within a population to the overall population niche to estimate the degree that resource use differs between individuals (Bolnick et al. 2003). Further information on ecological specialisation can also be provided by resource selection functions. In contrast to specialisation indices, which provide a single measure of specialisation integrated across all resources categories, resource selection functions calculate selectivity for individual resource categories (e.g. Dirnwoeber and Herler 2007; Graham 2007). These functions determine whether an individual resource is used significantly more or less than expected based on its availability (Manly et al. 2002), potentially enabling predictions of how species may respond to changes in resource availability and allowing the detection of key resources that may be critical to species persistence.

Here, we compare the performance of specialisation indices using coral-feeding butterflyfishes as a model group. Using a single dataset, levels of dietary specialisation in three species of coral-feeding butterflyfishes (Chaetodontidae) around Lizard Island in the Northern Great Barrier Reef, Australia, are calculated using four different indices of specialisation - a count of the total number of prey types consumed, the Shannon-Wiener diversity index, a chi-square log likelihood index that incorporates a measure of resource availability, and an among-individual specialisation index. We then calculate resource 
101 selection functions to investigate how individual resources are used in relation to their

102 availability. To investigate how spatial variation in resource availability may affect estimates

103 of specialisation, we compared levels of dietary specialisation and resource selection

104 functions for each species across three sites in exposed front reef habitats and three sites in

105 sheltered back reef habitats that differ in the composition and abundance of scleractinian

106 corals which these fish feed on. Unlike many other organisms for which dietary composition

107 has to be inferred through stomach content analysis or scat analysis, the dietary composition

108 of butterflyfishes can be directly quantified via in-situ observations of feeding behaviour,

109 allowing highly accurate and detailed estimation of dietary specialisation. Furthermore, the

110 availability of dietary resources can be directly measured with ease at the same locations

111 where feeding is observed (Pratchett 2005). Previous research has shown that coral-feeding

112 butterflyfishes vary in their level of dietary specialisation (e.g. Pratchett 2005, 2007) and in

113 their response to changes in resource availability, with specialised butterflyfishes showing the

114 greatest declines in abundance following coral loss on reefs (e.g. Pratchett et al. 2004;

115 Pratchett et al. 2006; Graham 2007; Wilson et al. 2006). These characteristics make coral-

116 feeding butterflyfishes appropriate models for general principles of ecological specialisation.

118 Our aims were to (i) quantify the dietary preferences of 3 butterflyfish species across habitats

119 with differing levels of resource availability; (ii) investigate how estimates of dietary

120 specialisation vary with the use of different specialisation indices; (iii) determine which

121 specialisation indices best inform predictions of vulnerability to environmental change; and

122 (iv) assess the utility of resource selection functions to inform predictions of vulnerability to

123 environmental change. We expected that the level of dietary specialisation calculated for each

124 species would vary between exposed and sheltered sites that differed in the availability of 
coral prey resources. We also expected estimates of specialisation to vary between the four different specialisation indices for each species.

127

\section{Methods} northern section of the Great Barrier Reef, Australia. Sampling was conducted across six sites around the island, representative of exposed front reef and sheltered back reef habitats. Lizard Head, Bird Islet, and South Island are directly exposed to the prevailing winds and represent

134 front reef habitats. Corner Beach, Osprey Islet and Vickies are relatively sheltered, large patch reefs, representative of back reef habitats. Sampling was conducted in $2-5 \mathrm{~m}$ depth along the reef crest at front reef sites, and along the tops of reefs in $3-6 \mathrm{~m}$ depth at back reef sites.

137

\section{STUDY SITES}

This study was carried out in November 2008 at Lizard Island (14\%40’S, $\left.145^{\circ} 27^{\prime} \mathrm{E}\right)$, in the

\section{RESOURCE AVAILABILITY}

Variation in the availability of coral prey was assessed using $50 \mathrm{~m}$ point intercept transects. At each site, five replicate transects were randomly placed along the reef crest or reef top in the same area where feeding observations took place. For each transect, the substrate directly beneath 50 sampling points was recorded to species level for corals, and to broad categories for all other substrate types (e.g., reef substrate, macroalgae). Variation in coral cover and community composition among sites was assessed using a nested MANOVA, which compared the mean abundance of the most common corals (grouped into 9 taxa) between sites nested within habitat types. Data were arc-sin transformed to satisfy assumptions of multivariate homogeneity and normality. Pillai's trace statistic was used to determine the significance of MANOVA results. Patterns in the coral composition at each site were explored using a canonical discriminant analysis (CDA). To assist with interpretation of the 
150 CDA, structural co-efficients of the 9 coral taxa were plotted as vectors to indicate the

151 predominant taxa at each site.

152

\section{FEEDING OBSERVATIONS}

154 Feeding observations were conducted for three common and widespread species of butterflyfishes; Chaetodon citrinellus, C. lunulatus, and C. trifascialis. Chaetodon citrinellus

156 is a facultative corallivore, consuming hard corals in addition to soft corals, other macro-

157 invertebrates and non-coral prey items, while $C$. trifascialis and $C$. lunulatus are obligate

158 corallivores, both feeding almost exclusively on hard (scleractinian) corals (Pratchett 2005).

159 The dietary preferences and proportional use of different prey types for each species were

160 determined from field observations of feeding behaviour across the six sites. Individual

161 butterflyfishes were randomly selected and followed at a distance of 2 - 5 metres for a 3-

162 minute period. The total number of bites taken from each species of coral, other non-coral

163 macro-invertebrates, and non-coral substrata during each observation was recorded, following

164 Pratchett (2005). Twenty observations for each species were conducted on adult fish

165 throughout the day at each site. Every effort was made to ensure that individual fish were not

166 observed more than once. Variation in dietary composition of the three species was analysed

167 using a nested multivariate analysis of variance (MANOVA), which simultaneously compared

168 the mean number of bites taken from each of 15 major prey types at each site, nested within

169 habitat type. Pillai's trace statistic was used to determine the significance of MANOVA

170 results.

171

172 DIETARY SPECIALISATION AND SELECTIVITY

173 To investigate how different specialisation indices may vary in their estimates of

174 specialisation, dietary specialisation for each species at each site was assessed using four 
175 different indices - a simple count of the total number of different prey types consumed, the

176 Shannon-Wiener diversity index (Zar 1999), the Chi square log likelihood statistic $\mathrm{X}_{\mathrm{L} 2}^{2}$

177 (Manly et al. 2002) and an index of among-individual dietary specialisation (Araujo et al.

178 2008). For calculation of the Shannon-Wiener diversity index, the log likelihood statistic and

179 among-individual dietary overlap, all dietary items were grouped into 15 major prey

180 categories (listed in Table 3) and indices were calculated based on these categories. Dietary

181 selectivity for each species at each site was assessed using resource selection functions

182 (Manly et al. 2002), which were also calculated based on 15 major prey categories.

183

184 The Shannon-Wiener diversity index assesses specialisation based on the number and

185 evenness of different prey categories consumed and was calculated using the formula:

186

187

188

$H^{\prime}=-\sum p_{i} \log p_{i}$

eqn 1.

189

$\mathrm{i}=1$

190

191 where $\mathrm{k}$ is the number of prey categories and $\mathrm{p}_{\mathrm{i}}$ is the proportional use of each prey category (Zar 1999). Values of H' can range from zero to one, with lower values indicating increasing specialisation.

194

195 The Chi square log-likelihood statistic $\mathrm{X}_{\mathrm{L} 2}{ }^{2}$, was calculated following Manly et al. (2002). As

196 data were collected on selection of resource units by individual animals, but resource

197 availability was assessed at the population level, Model Design II with Sampling Protocol A

198 was used (Manly et al. 2002, eq 4.27). $\mathrm{X}_{\mathrm{L} 2}{ }^{2}$ was calculated using the formula:

199 


$$
\mathrm{j}=1 \quad \mathrm{i}=1
$$

where $\mathrm{u}_{\mathrm{ij}}$ is the proportional use of each prey type (i) by each individual (j) and $E\left(\mathrm{u}_{\mathrm{ij}}\right)$ is the expected number of bites taken from prey type $\mathrm{i}$ by the $\mathrm{jth}$ individual if use is proportional to availability (Manly et al. 2002). The resulting value of $\mathrm{X}_{\mathrm{L} 2}{ }^{2}$ was compared to the chi-squared distribution with $n(I-1)$ degrees of freedom (where I is the total number of prey categories) to determine the significance of selectivity exhibited by each butterflyfish species at each site.

Higher values of $\mathrm{X}_{\mathrm{L} 2}{ }^{2}$ indicate increasing specialisation.

Variation in dietary composition between individual butterflyfishes (among-individual specialisation) was assessed using an individual niche overlap network following Araujo et al. (2008). For each species at each site a niche overlap network was defined using the programme DIETA1.0 (Araujo et al. 2008) in which the nodes of the network represented 215 individual fishes and the connections between nodes measured the degree of dietary overlap 216 among pairs of individuals. Each connection was assigned a weight $\left(\mathrm{w}_{\mathrm{ij}}\right)$ ranging from 0 for no overlap to 1 for total overlap $\left(0<\mathrm{w}_{\mathrm{ij}}>1\right)$ as a measure of the pairwise dietary overlap 218 between individuals $\mathrm{i}$ and $\mathrm{j}$. Among-individual dietary variation (E) was then measured as the 219 average density of all connections in the network, quantified as $\mathrm{E}=1-\overline{\mathrm{w}} \mathrm{ij}$. Low values of $\mathrm{E}$ 220 indicate that there is little individual dietary specialisation, with E equal to 0 when all 221 individuals have identical diets; high values of $\mathrm{E}$ indicate that individual dietary specialisation 222 is high, with E equal to 1 when each individual uses a unique resource. If individual-level specialisation is high, then species-level specialisation is generally low. Monte Carlo

224 bootstrap simulations were run using DIETA1.0 for each species at each site to test the null 
hypothesis that any observed dietary variation arose from individuals sampling stochastically

226 from a shared distribution (Araujo et al. 2008). In these simulations each individual was reassigned the same number bites that it was observed taking, drawn randomly from the observed distribution of the population diet via multinomial sampling. 10,000 such populations were simulated and among individual dietary variation, E, was recalculated for each simulated population. The null hypothesis was rejected if the empirical (observed value)

$231 E$ was higher than $95 \%$ of the $E$ values of the simulated populations.

To investigate dietary selectivity and determine which prey corals were used significantly more or less frequently than expected, resource selection functions were calculated for major prey corals for each species at each site following Manly et al.'s (2002) Model Design II,

236 Sampling Protocol A, using the formula:

n

$$
\mathrm{j}=1
$$

where $u_{i}$ is the proportional use of prey category $i$ by the jth individual, $n$ is the number of

243 individuals sampled and $\mathrm{p}_{\mathrm{i}}$ is the proportional availability of each prey category within each

244 site. These functions allow for sampling of resource use at the individual level and resource 245 availability at the population level (Manly et al. 2002, eq 4.29). Bonferroni corrected 95\% 246 confidence intervals were calculated around each selection function such that the use of a 247 particular prey was deemed to be significantly disproportionate to its availability if the $95 \%$ 248 confidence interval did not encompass one (Manly et al. 2002). Selection functions 249 significantly greater than one indicated selection (i.e. coral prey was consumed significantly 
more than expected based on availability); selection functions significantly less than one indicated avoidance (i.e. coral prey was consumed significantly less than expected based on availability).

\section{Results}

\section{CORAL COVER AND COMPOSITION}

Cover and community composition of scleractinian corals varied among habitat types and sites. Cover of scleractinian corals was highest at exposed sites, covering $51 \%( \pm 3.7)$ of hard substrate at South Island, and $41 \%( \pm 3.0)$ and $40 \%( \pm 0.9)$ of hard substrate at Lizard Head and Bird Islet respectively. At sheltered sites, cover of scleractinian corals was highest at Osprey Islet ( $32 \% \pm 3.5$ of hard substrate) and Vickies ( $32 \% \pm 4.5$ of hard substrate), and lowest at Corner Beach ( $29 \% \pm 5.6$ of hard substrate). Variation in coral community composition was highly significant among habitats (MANOVA, Pillai's trace $=14.1, \mathrm{df}=9,16$, $\mathrm{P}<0.001$ ) and sites (MANOVA, Pillai's trace $=2.6, \mathrm{df}=36,76, \mathrm{P}<0.001$ ). Exposed sites were characterised by a high abundance of tabular and digitate Acropora corals, while sheltered sites were dominated by soft corals (family Alcyonacea) (Fig. 1).

\section{DIETARY COMPOSITION}

Chaetodon citrinellus fed predominantly on hard corals at each site (taking between 39 to $75 \%$ of all bites from hard corals), but also supplemented its diet with small amounts of soft corals, other non-coral macro invertebrates and bites on reef substrates (Table 1).

Consumption of hard corals was highest at exposed sites where hard corals were more abundant. Both $C$. lunulatus and $C$. trifascialis fed almost exclusively on hard corals at all sites. Chaetodon lunulatus took between 96 to $99 \%$ of all bites from hard corals, while $C$. trifascialis took $100 \%$ of all bites from hard corals at all sites except Lizard Head (Table 1). 
275 Dietary composition varied significantly (MANOVA, $\mathrm{P}<0.05$ ) for all three species between 276 habitats and sites (Table 2).

The number of prey types consumed was similar for $C$. citrinellus and $C$. lunulatus and both species consumed a greater number of prey types at exposed sites compared to sheltered sites (Fig. 2). Chaetodon trifascialis consumed almost the same number of prey types at both sheltered and exposed sites and consumed fewer types than both $C$. citrinellus and $C$. lunulatus. Dietary evenness (indicated by the Shannon Wiener index) was relatively high for both $C$. citrinellus and C. lunulatus, but was low for C. trifaiscialis (Fig. 2). For all three species, dietary evenness varied between sites. Evenness was higher at exposed sites for $C$. citrinellus, comparable across all sites for $C$. lunulatus and higher at sheltered sites for $C$. trifaiscialis.

Based on significant differences in the proportional consumption versus availability of different coral prey, all three species showed highly significant dietary selectivity at each site $(\mathrm{P}<0.001$ for all species, Table 3). Patterns of dietary selectivity indicated by the Chi square $\log$-likelihood statistic $\left(X_{\mathrm{L} 2}^{2}\right)$ were different to patterns of dietary evenness indicated by the Shannon Wiener index and levels of specialisation estimated using a count of total number of prey categories consumed. Chaetodon trifascialis was the most selective, closely followed by C. lunulatus, while C. citrinellus was the least selective. Selectivity was higher at sheltered 296 sites compared to exposed sites for all three species (Fig. 2).

298 Chaetodon citrinellus showed a high degree of dietary versatility, consuming a number of 299 different hard coral taxa at each site (Table 1) and resource selection functions indicated that 
C. citrinellus was a fairly generalised feeder (Table 3). Significant selectivity or avoidance

301 was only shown for a few prey categories and most categories were consumed in proportion 302 to their availability (Table 3).

303

304 Although overall dietary selectivity $\left(X_{\mathrm{L} 2}^{2}\right)$ was high for $C$. lunulatus at each site and 305 comparable to that of $C$. trifascialis (Fig. 2), resource selection functions for individual coral 306 taxa indicated that $C$. lunulatus was a much more generalised feeder (Table 3). Chaetodon 307 lunulatus consumed a large number (between 25 and 34) of different hard coral taxa at each 308 site (Table 1) and only showed avoidance of non hard coral prey categories (Table 3). At 309 exposed sites $C$. lunulatus exhibited significant feeding selectivity for Acropora corals and 310 Pocillopora corals, but fed on most hard coral prey categories in proportion to their 311 availability across both exposed and sheltered sites.

313 In contrast, $C$. trifascialis had much more specialised feeding preferences, consuming 17 or 314 fewer different hard coral taxa at each site (Table 1) and never using a large number of hard 315 coral taxa across all sites, regardless of their availability (Table 3). Chaetodon trifascialis only 316 fed on corals from three genera - Acropora, Pocillopora and Montipora - and only showed 317 selectivity for Acropora corals (Table 3), taking more than $90 \%$ of all bites from Acropora 318 corals at each site. Particularly strong selectivity was exhibited for Acropora hyacinthus, with 319 C. trifascialis taking between 45 and $78 \%$ of all bites from this species at each site.

321 All three species showed significant among-individual dietary variation at each site $(\mathrm{P}<0.001$, 322 Monte Carlo simulations). Both C. citrinellus and C. lunulatus showed high levels of among 323 individual dietary variation across all sites ( $\mathrm{E}>0.5$, Individual niche overlap network), while 
C. trifascialis showed some among individual dietary variation at sheltered sites and low

325 levels of among individual dietary variation at exposed sites (Fig. 2).

\section{Discussion}

328 The strengths and weaknesses of different specialisation indices have been reviewed several

329 times, and most recently by DeVictor et al. (2010), but this is the first study to directly

330 compare the performance of such indices using the same dataset. Similarly, the link between

331 specialisation and vulnerability has been explored in depth (e.g. Colles et al. 2009), but there

332 has been little consideration of how the measurement of specialisation may affect estimates of

333 vulnerability. To our knowledge this is the first study to investigate the utility of different

334 specialisation indices within the context of predicting vulnerability to environmental change.

335 We found that the level of dietary specialisation estimated for all three butterflyfish species

336 varied when different specialisation indices were used, indicating that the choice of index can

337 have a considerable impact upon estimates of the degree of specialisation. These impacts are

338 likely to be less important for generalist species. For example patterns of dietary

339 specialisation for $C$. citrinellus, the most generalist of the three study species, were similar

340 between all four specialisation indices. But for species that are neither true generalists nor

341 extreme specialists, indices based solely on patterns on resource use (e.g. Shannon-Wiener

342 index) may give somewhat different estimates of specialisation to indices which incorporate

343 resource availability (e.g. Chi square selectivity index). Chaetodon lunulatus feeds almost

344 exclusively on hard corals and therefore could be considered to have a specialised diet, yet it

345 feeds across a broad range of hard coral species and is considered more of a generalist feeder

346 within the butterflyfishes that are obligate corallivores (Pratchett 2005; 2007). Specialisation

347 levels estimated by the Shannon Wiener index for $C$. lunulatus were similar to those of the 
generalist $C$. citrinellus, while specialisation levels estimated by the Chi square index (which considers resource availability) were more similar to those of the specialist $C$. trifascialis.

351 The importance of incorporating resource availability into specialisation estimates has long 352 been recognised by ecologists (Hurlbert 1978; Petraitis 1979). Although the use of indices 353 which only evaluate patterns of resource use is no longer as widespread as it once was (see 354 MacNally 1995), many current studies continue to use these types of indices to measure specialisation (e.g. Kotze and O'Hara 2003; Munday 2004; Charrette et al. 2006; Julliard et al. 2006; Christensen and Kleindorfer 2009). Specialisation indices which ignore resource availability may be highly misleading as a species that uses only a few resources will be classified as a specialist, even if those resources are highly abundant (Hurlbert 1978). In contrast, when specialisation indices incorporating measures of resource availability are used, a species will only be classified as a specialist if resources are used disproportionately to their availability. Some may believe this distinction is a somewhat semantic issue and may argue that regardless of whether or not resource availability is considered, any type of specialisation 363 index will always classify extreme specialists as such. However, resource use may actually 364 reflect patterns of resource availability rather than specialisation per se. Specialisation indices that do not consider resource availability will be unable to distinguish between a species using

366 a few commonly available resources and one that uses a narrow subset of available resources.

367 Both types of species will be classified as extreme specialists, even though the first species

368 may actually have a generalised ecology and utilise a large number of resources in cases

369 where it is not limited by resource availability (e.g. Pampas fox, Varela et al. 2008). While any species using resources which are threatened will be at risk of extinction, in the context of

371 predicting vulnerability, a species that uses resources disproportionately to their availability is

372 much more likely to be vulnerable to changes in the abundance of those resources than a 
373 species that uses a few commonly available resources. Therefore, the use of specialisation

374 indices that incorporate measures of resource availability is preferable if specialisation is used 375 as a proxy for vulnerability.

377 Consideration of several locations or time periods is also essential when quantifying

378 ecological specialisation in order to understand responses to changes in resource availability

379 (Devictor et al. 2010). The degree of specialisation estimated for all three species in this study 380 varied between individual sites and habitats. Consideration of specialisation patterns at only a 381 single site (e.g. Pratchett 2007) may have resulted in specialisation estimates that were not 382 reflective of the true versatility of each species. It is possible that species classified as 383 specialists based on studies in a single location may only be functioning as specialists on a 384 local scale, and across their entire geographic range these species may in fact have generalised 385 ecologies (Fox and Morrow 1981). For example, on the south coast of Japan two species of 386 decorator crab (Micippa platipes and Tiarinia cornigera) were highly selective in their 387 preferences for algae, but on the north coast both species showed no selectivity (Hultgren et 388 al. 2006). Consideration of temporal and spatial variation in specialisation is crucial in 389 systems where resources can become depleted (e.g. Pratchett et al. 2006) or where the 390 availability of resources may vary seasonally (e.g. Varela et al. 2008) in order to accurately 391 determine specialisation and predict vulnerability.

393 Understanding how ecological specialisation varies between individuals within a population 394 may also be important in predicting how a species will respond to changes in resource 395 availability. A population of individuals each specialising on a different resource may still 396 look like a "generalist" species by some measures, but such a population may respond 397 differently to resource depletion than another population composed of individual generalists. 
Theory suggests that populations of individual specialists may be more stable and open to

399 future evolutionary diversification (Bolnick et al. 2003; Kendall and Fox 2002, 2003).

400 Furthermore, niche variation within a population may help to buffer against loss of particular

401 habitats or resources and provide genetic variation needed to adapt to changing environments

402 (Bolnick et al. 2003; Durell 2000). In cases where estimation of resource availability is not

403 possible, measurement of among-individual variation in resource use may provide additional

404 information about ecological specialisation and vulnerability to that gained from the use of

405 traditional niche breadth measures. As highly specialised species are likely to have low levels

406 of among-individual variation due to their narrow niche breadth, use of among-individual

407 specialisation indices may be most informative when comparing vulnerability of species with

408 more generalised ecologies.

409

410 Resource selection functions provide fine scale information on ecological specialisation,

411 enabling greater insights into the potential response of species to changes in resource

412 availability, and therefore vulnerability to future environmental changes, than can be gained

413 from overall estimates of specialisation. Although overall levels of dietary specialisation

414 estimated by the Chi square selectivity index were similar for C. lunulatus and C. trifascialis,

415 resource selection functions indicated that the diet of $C$. trifascialis was much more

416 specialised and its feeding preferences were more conserved, both in the terms of the number

417 of resources it showed selectivity for and in the spatial variation of its selectivity.

418 Consequently, C. trifascialis is likely to be highly vulnerable to changes in resource

419 availability, particularly to changes in the abundance of the Acropora corals that it

420 preferentially feeds on (Pratchett 2005; 2007). In contrast, C. lunulatus utilised a large

421 number of resources at each site and selectivity of specific dietary items varied between sites

422 which also varied in their resource availability. These findings suggest that even though $C$. 
lunulatus has a reasonably specialised diet, it is likely to be fairly resilient to changes in resource availability. Such responses to changes in resource availability have already been reported for both species. In French Polynesia, the abundance of $C$. trifascialis declined by almost $100 \%$ following declines in the abundance of its preferred Acropora corals (Berumen and Pratchett 2006), while on the Great Barrier Reef, C. lunulatus has been shown to alter its diet in response to a loss of some coral taxa (Pratchett et al. 2004). These responses highlight the predictive value of resource selection functions and provide justification for their use in the identification of key resources which may be critical to a species' persistence.

In addition to current threats, effective conservation strategies need to consider future threats to habitats and the potential resultant habitat composition. For coral reefs, the frequency of mass bleaching events, disease and mortality are predicted to increase as a result of anthropogenic climate change (Hoegh-Guldberg et al. 2007). As the dietary preferences of $C$. trifascialis are highly conserved - the same coral prey was selected at each site regardless of availability - we can predict that this species is likely to have a very low capacity to respond to changes in the availability of coral prey. Acroporid corals, including Acropora hyacinthus, the preferred prey of $C$. trifascialis, are highly susceptible to bleaching (Marshall and Baird 2000), and the abundance of these corals is likely to decline in the future with increased frequency of bleaching events. Consequently, the vulnerability of $C$. trifascialis to the impacts of climate change on coral reefs is only likely to increase and this species should be assigned a high extinction risk based on its level of dietary specialisation.

While the example presented here comes from a single family of coral reef fishes, we believe the butterflyfishes are useful models for understanding more general trends and that these findings reflect ecological principles that transcend the system. Calculating the four 
448 specialisation indices from the same dataset removes any variation that might have resulted

449 from simply comparing the findings of several independent studies. Consequently, we are

450 confident that the differences in the levels of specialisation estimated by each of the four

451 indices reflect actual differences and not sampling effects. The three species we included in

452 our analysis displayed a range of specialisation levels, from generalist to extreme specialist,

453 and provide an indication of how these indices are likely to perform across species with

454 varying levels of specialisation. Moreover, the comparison of two differing habitats illustrates

455 how estimates of specialisation may be affected by temporal or spatial differences in resource

456 availability.

458 CONCLUSIONS

459 This is the first study to compare the effects of using different indices on estimates of

460 ecological specialisation and predictions of vulnerability. While we recognise realistic

461 limitations of decision makers in conducting extensive assessments, our results demonstrate

462 that vulnerability assessments based on a single specialisation index may be misleading and

463 the best estimates of specialisation will be provided by indices which incorporate resource

464 availability measures. Furthermore, the use of resource selection functions in addition to

465 overall specialisation indices will provide a more accurate picture of ecological versatility and

466 therefore vulnerability to future environmental changes. For example, the highly conserved

467 dietary preferences and high specialisation values estimated for C. trifascialis in this study

468 suggest that this species is likely to be highly vulnerable to the impacts of climate-induced

469 coral loss on reefs.

470

471 Acknowledgements 
472 We thank A. Cole, D. Coker, D. McCowan and K. Chong-Seng for assistance with field work.

473 We also thank the Lizard Island Research Station staff for logistic support. This research was

474 funded in part by a Queensland Government Smart State PhD Scholarship and a Wildlife

475 Preservation Society of Australia grant to RJL and a Sir Keith Murdoch Fellowship from the

476 American Australian Association to MLB. This manuscript was greatly improved by the

477 comments of four anonymous reviewers.

478 


\section{References}

Aitken KEH, Martin K (2008) Resource selection plasticity and community responses to experimental reduction of a critical resource. Ecology 89:971-980

Araujo MS, Gonzaga MO (2007) Individual specialization in the hunting wasp Trypoxylon (Trypargilum) albonigrum (Hymenoptera, Crabronidae). Behav. Ecol. Sociobiol. 61:1855-1863

Araujo MS et al. (2008) Network analysis reveals contrasting effects of intraspecific competition on individual vs. population diets. Ecology 89:1981-1993

Berumen ML, Pratchett MS (2006) Recovery without resilience: persistent disturbance and long-term shifts in the structure of fish and coral communities at Tiahura Reef, Moorea. Coral Reefs 25:647-653

Bolnick DI et al. (2003) The ecology of individuals: Incidence and implications of individual specialization. Am. Nat. 161:1-28

Bottrill MC et al. (2008) Is conservation triage just smart decision making? Trends Ecol. Evol. 23:649-654

Chapin FS et al. (2000) Consequences of changing biodiversity. Nature 405:234-242

Charrette NA, Cleary DFR, Mooers AO (2006) Range-restricted, specialist Bornean butterflies are less likely to recover from ENSO-induced disturbance. Ecology 87:23302337

Christensen R, Kleindorfer S (2009) Jack-of-all-trades or master of one? Variation in foraging specialisation across years in Darwin's Tree Finches (Camarhynchus spp.). J. Ornithol. $150: 383-391$

Colles A, Liow LH, Prinzing A (2009) Are specialists at risk under environmental change? Neoecological, paleoecological and phylogenetic approaches. Ecol. Lett. 12:849-863 
Devictor, V., Clavel, J., Julliard, R., Lavergne, S., Mouillot, D., Thuiller, W., Venail, P., Villeger, S. \& Mouquet, N. (2010) Defining and measuring ecological specialization. J. App. Ecol., 47:15-25.

Dirnwoeber M, Herler J (2007) Microhabitat specialisation and ecological consequences for coral gobies of the genus Gobiodon in the Gulf of Aqaba, northern Red Sea. Mar EcolProg Ser 342:265-275

Dulvy NK, Sadovy Y, Reynolds JD (2003) Extinction vulnerability in marine populations. Fish. Fish. 4:25-64

Durell S (2000) Individual feeding specialisation in shorebirds: population consequences and conservation implications. Biol. Rev. 75:503-518

Eeley HAC, Foley RA (1999) Species richness, species range size and ecological specialisation among African primates: geographical patterns and conservation implications. Biodivers. Conserv. 8:1033-1056

Fisher DO, Blomberg SP, Owens IPF (2003) Extrinsic versus intrinsic factors in the decline and extinction of Australian marsupials. Proc. R. Soc. Lond. Ser. B-Biol. Sci. 270:18011808

Fisher DO, Owens IPF (2004) The comparative method in conservation biology. Trends Ecol. Evol. 19:391-398

Fox LR, Morrow PA (1981) Specialization - species property or local phenomenon. Science

$$
\text { 211:887-893 }
$$

Gardiner NM, Jones GP (2005) Habitat specialisation and overlap in a guild of coral reef cardinalfishes (Apogonidae). Mar Ecol-Prog Ser 305:163-175

Graham NAJ (2007) Ecological versatility and the decline of coral feeding fishes following climate driven coral mortality. Mar Biol 153:119-127

Harcourt AH, Coppeto SA, Parks SA (2002) Rarity, specialization and extinction in primates. 
529 Hoegh-Guldberg O et al. (2007) Coral reefs under rapid climate change and ocean acidification. Science 318:1737-1742

531 Hurlbert SH (1978) Measurement of niche overlap and some relatives. Ecology 59:67-77

532 Hultgren, K.M., Thanh, P.D. and Sato, M. (2006) Geographic variation in decoration selectivity of Micippa platipes and Tiarinia cornigera in Japan. Mar Ecol-Prog Ser, $326,235-244$.

James AN, Gaston KJ, Balmford A (1999) Balancing the Earth's accounts. Nature 401:323324

Julliard, R., Clavel, J., Devictor, V., Jiguet, F. and Couvet, D. (2006) Spatial segregation of specialists and generalists in bird communities. Ecol Lett 9, 1237-1244.

Kendall BE, Fox GA (2002) Variation among individuals and reduced demographic stochasticity. Conserv. Biol. 16:109-116

Kendall BE, Fox GA (2003) Unstructured individual variation and demographic stochasticity. Conserv. Biol. 17:1170-1172

Kotze DJ, O'Hara RB (2003) Species decline - but why? Explanations of carabid beetle (Coleoptera, Carabidae) declines in Europe. Oecologia 135:138-148

MacNally RC (1995) Ecological Versatility and Community Ecology. Cambridge University Press, Cambridge

Manly BFJ, McDonald LL, Thomas DL, McDonald TL, Erickson WP (2002) Resource Selection by Animals, Statstical Design and Analysis for Field Studies, 2nd edn. Kluwer Academic Publishers, Dordrecht

Marshall PA, Baird AH (2000) Bleaching of corals on the Great Barrier Reef: differential susceptibilities among taxa. Coral Reefs 19:155-163

552 McKinney ML (1997) Extinction vulnerability and selectivity: Combining ecological and 
554 Munday PL (2004) Habitat loss, resource specialization, and extinction on coral reefs. Glob Change Biol 10:1642-1647

556 Owens IPF, Bennett PM (2000) Ecological basis of extinction risk in birds: Habitat loss versus human persecution and introduced predators. Proc. Natl. Acad. Sci. U. S. A.

97:12144-12148

559 Petraitis PS (1979) Likelihood measures of niche breadth and overlap. Ecology 60:703-710

560 Pratchett MS (2005) Dietary overlap among coral-feeding butterflyfishes (Chaetodontidae) at Lizard Island, northern Great Barrier Reef. Mar Biol 148:373-382

562 Pratchett MS (2007) Dietary selection by coral-feeding butterflyfishes (Chaetodontidae) on the Great Barrier Reef, Australia. Raffles Bull. Zool.:171-176

564 Pratchett MS et al. (2008) Effects of climate-induced coral bleaching on coral-reef fishes Ecological and economic consequences. In: Oceanography and Marine Biology: an Annual Review, Vol 46, vol 46. Crc Press-Taylor and Francis Group, Boca Raton, pp $251-296$

Pratchett MS, Wilson SK, Baird AH (2006) Declines in the abundance of Chaetodon butterflyfishes following extensive coral depletion. J Fish Biol 69:1269-1280

Pratchett MS, Wilson SK, Berumen ML, McCormick MI (2004) Sublethal effects of coral bleaching on an obligate coral feeding butterflyfish. Coral Reefs 23:352-356

572 Purvis A, Gittleman JL, Cowlishaw G, Mace GM (2000a) Predicting Extinction Risk in Declining Species. P Roy Soc B-Biol Sci 267:1947-1952

574 Purvis A, Jones KE, Mace GM (2000b) Extinction. Bioessays 22:1123-1133

575 Safi K, Kerth G (2004) A comparative analysis of specialization and extinction risk in temperate-zone bats. Conserv. Biol. 18:1293-1303

577 Thomas CD et al. (2004) Extinction risk from climate change. Nature 427:145-148 
578 Varela O, Cormenzana-Mendez A, Krapovickas L, Bucher EH (2008) Seasonal diet of the

579 Pampas fox (Lycalopex gymnocercus) in the chaco dry woodland, northwestern

$580 \quad$ Argentina. J. Mammal. 89:1012-1019

581 Wilson SK, Graham NAJ, Pratchett MS, Jones GP, Polunin NVC (2006) Multiple

582 disturbances and the global degradation of coral reefs: are reef fishes at risk or resilient?

$583 \quad$ Glob Change Biol 12:2220-2234.

584 Zar JH (1999) Biostatistical Analysis, 4th edn. Prentice Hall, New Jersey 


\section{Table 1}

Dietary composition of Chaetodon citrinellus, C. lunulatus and C. trifascialis at 3 exposed front reef sites (Bird Islet, Lizard Head, South Island) and 3 sheltered back reef sites (Corner Beach, Osprey Islet, Vickies) at Lizard Island, Great Barrier Reef.

\begin{tabular}{|c|c|c|c|c|c|c|}
\hline \multirow{5}{*}{ Species } & \multirow{5}{*}{ Site } & \multirow{2}{*}{$\begin{array}{l}\text { Hard } \\
\text { corals }\end{array}$} & \multirow{2}{*}{$\begin{array}{l}\text { Soft } \\
\text { corals }\end{array}$} & \multirow{2}{*}{$\begin{array}{l}\text { Other macro } \\
\text { invertebrates }\end{array}$} & \multirow{2}{*}{$\begin{array}{l}\text { Imperceptible } \\
\text { items }^{1}(\%)\end{array}$} & \multirow{2}{*}{$\begin{array}{l}\text { Total } \\
\text { number hard }\end{array}$} \\
\hline & & & & & & \\
\hline & & $(\%)$ & $(\%)$ & $(\%)$ & & coral \\
\hline & & & & & & species \\
\hline & & & & & & consumed \\
\hline \multirow[t]{6}{*}{ C. citrinellus } & Bird Islet & 75.3 & 1.1 & 2.4 & 21.1 & 23 \\
\hline & Lizard Head & 55.9 & 6.8 & 3.1 & 34.2 & 21 \\
\hline & South Island & 74.9 & 1.3 & 2.5 & 21.3 & 29 \\
\hline & Corner Beach & 39.1 & 3.0 & 2.5 & 55.5 & 18 \\
\hline & Osprey Islet & 49.6 & 0.0 & 0.0 & 50.4 & 12 \\
\hline & Vickies & 59.5 & 11.8 & 1.6 & 27.1 & 28 \\
\hline \multirow[t]{6}{*}{ C. lunulatus } & Bird Islet & 98.6 & 0.4 & 0.5 & 0.5 & 34 \\
\hline & Lizard Head & 99.6 & 0.0 & 0.0 & 0.4 & 25 \\
\hline & South Island & 99.0 & 0.2 & 0.0 & 0.8 & 27 \\
\hline & Corner Beach & 99.2 & 0.0 & 0.0 & 0.8 & 26 \\
\hline & Osprey Islet & 100.0 & 0.0 & 0.0 & 0.0 & 26 \\
\hline & Vickies & 96.2 & 0.0 & 3.4 & 0.4 & 26 \\
\hline \multirow[t]{3}{*}{ C. trifascialis } & Bird Islet & 100.0 & 0.0 & 0.0 & 0.0 & 15 \\
\hline & Lizard Head & 99.4 & 0.0 & 0.0 & 0.6 & 14 \\
\hline & South Island & 100.0 & 0.0 & 0.0 & 0.0 & 17 \\
\hline
\end{tabular}




$\begin{array}{lccccc}\text { Corner Beach } & 100.0 & 0.0 & 0.0 & 0.0 & 15 \\ \text { Osprey Islet } & 100.0 & 0.0 & 0.0 & 0.0 & 14 \\ \text { Vickies } & 100.0 & 0.0 & 0.0 & 0.0 & 15\end{array}$

${ }^{1}$ Refers to bites taken on reef pavement, sand and rubble. It was assumed that these bites were targeting small motile invertebrates such as polychaetes and crustaceans. 
Table 2

MANOVA results for dietary composition of Chaetodon citrinellus, C. lunulatus and $C$. trifascialis among habitats (exposed front reef and sheltered back reef) and sites (Bird Islet, Lizard Head, South Island, Corner Beach, Osprey Islet, Vickies) nested within habitats at Lizard Island, Great Barrier Reef.

\begin{tabular}{lllll}
\hline Species & Source & Pillai’s trace & d.f. & P \\
\hline C. citrinellus & Habitat & 4.29 & 15,100 & $<0.001$ \\
& Site (Habitat) & 1.52 & 60,412 & $<0.05$ \\
C. lunulatus & Habitat & 5.52 & 15,100 & $<0.001$ \\
& Site (Habitat) & 2.82 & 60,412 & $<0.001$ \\
C. trifascialis & Habitat & 5.77 & 9,106 & $<0.001$ \\
& Site (Habitat) & 1.60 & 36,436 & $<0.02$ \\
\hline
\end{tabular}




\section{Table 3}

Dietary selectivity of Chaetodon citrinellus, C. lunulatus and C. trifascialis at 3 exposed front reef sites (Bird Islet, Lizard Head, South Island) and 3 sheltered back reef sites (Corner Beach, Osprey Islet and Vickies) at Lizard Island, Great Barrier Reef for 15 major prey categories. +: prey category used significantly more than expected (selected); -: prey category used significantly less than expected (avoided); U: prey category unused (strongly avoided); NA: prey category not available; blank cells indicate prey categories that were used in proportion to availability (neither selected nor avoided).

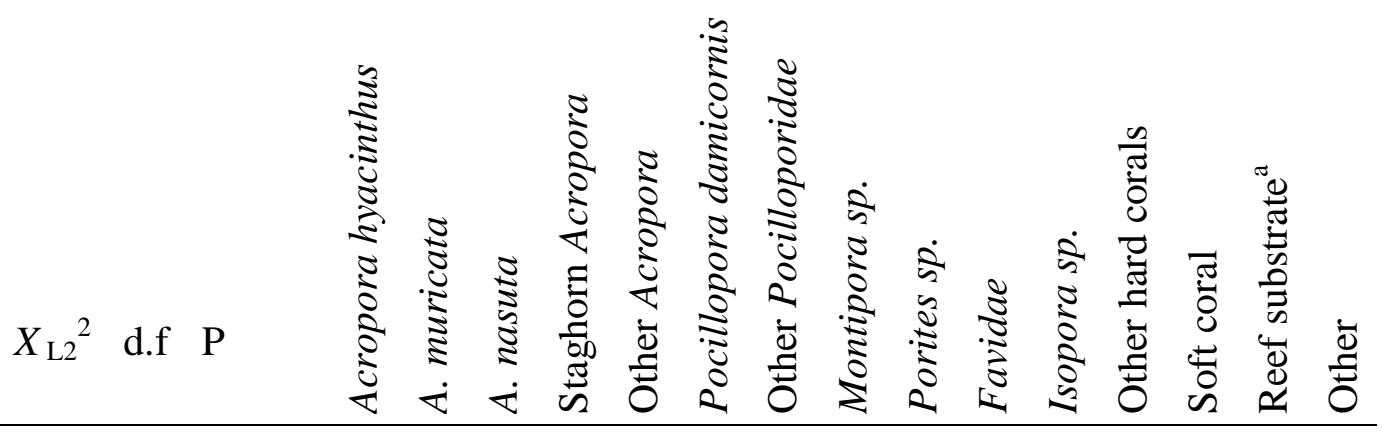

C. citrinellus

Exposed

Bird Islet $2103220<0.001 \quad$ U $\quad$ U $\quad+\quad+$

Lizard Head $1520220<0.001 \quad$ NA $\quad \mathrm{NA}+\quad+$

South Island $1557 \quad 240<0.001 \quad \mathrm{U}$

Sheltered

Corner Beach $1602180<0.001 \quad-\quad+\quad$ NA $\quad$ U NA U $\quad$ +

Osprey Islet $2227 \quad 180<0.001 \quad \mathrm{U}+\mathrm{NA}-\mathrm{NAU} \mathrm{U}+\mathrm{U}$

Vickies $\quad 2261 \quad 280<0.001$

C. lunulatus

Exposed 
Bird Islet $2731220<0.001+U$ $++$

Lizard Head $3390 \quad 180<0.001 \quad$ NA $\quad \mathrm{NA}+\quad+$ $U-U$

South Island $1869200<0.001+\quad$ U

Sheltered

Corner Beach $3928180<0.001$

$+\quad \mathrm{NA}$

NA $\quad U-U$

Osprey Islet $\quad 2950 \quad 180<0.001$

NA

NA $\quad$ U U U

Vickies

$2782240<0.001$

$+$

U -

C. trifascialis

Exposed

Bird Islet $\quad 3693 \quad 80<0.001+\quad U \quad U$

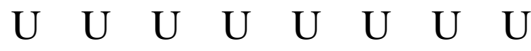

Lizard Head $3146100<0.001+$ NA NA

U $\quad \mathrm{U} \quad \mathrm{U} \quad \mathrm{U} \quad \mathrm{U} \quad \mathrm{U}-\mathrm{U}$

South Island $1969100<0.001+\quad U$

$+$

$\begin{array}{llllllll} & \mathrm{U} & \mathrm{U} & \mathrm{U} & \mathrm{U} & \mathrm{U} & \mathrm{U} & \mathrm{U}\end{array}$

Sheltered

Corner Beach $381080<0.001+$

Osprey Islet $4357 \quad 120<0.001+$

Vickies
- NANAU U NA U U U U

$+\quad$ NA $\quad$ U U NAU U U U

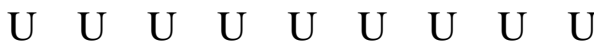

\footnotetext{
${ }^{\mathrm{a}}$ Includes reef pavement, sand and rubble. It was assumed that bites on reef substrates were targeting small motile invertebrates such as polychaetes and crustaceans.
} 


\section{Figure Legends}

Fig. 1

Canonical discriminant analysis showing coral assemblages at three exposed front reef sites (BI: Bird Islet; LH: Lizard Head; SI: South Island) and three sheltered back reef sites (OI: Osprey Islet; CB: Corner Beach; VI: Vickies) around Lizard Island, Great Barrier Reef. Circles plotted represent $95 \%$ confidence intervals around the group centriod for each site (unfilled circles: exposed sites; filled circles: sheltered sites). Vectors are structural coefficients indicating the relative abundance of the major coral taxa among the 6 sites.

\section{Fig. 2}

Dietary specialisation shown by Chaetodon citrinellus, C. lunulatus and C. trifascialis across 3 exposed front reef sites (Bird Islet, Lizard Head, South Island) and 3 sheltered back reef sites (Corner Beach, Osprey Islet, Vickies) at Lizard Island, Great Barrier Reef. Dietary specialisation is calculated using (A) total number of prey categories consumed; (B) Shannon Wiener index; (C) Chi square log likelihood statistic, $X_{\mathrm{L} 2}^{2}$; and (D) among-individual dietary variation, $E$. Data are means for each habitat type \pm 1 SE. 


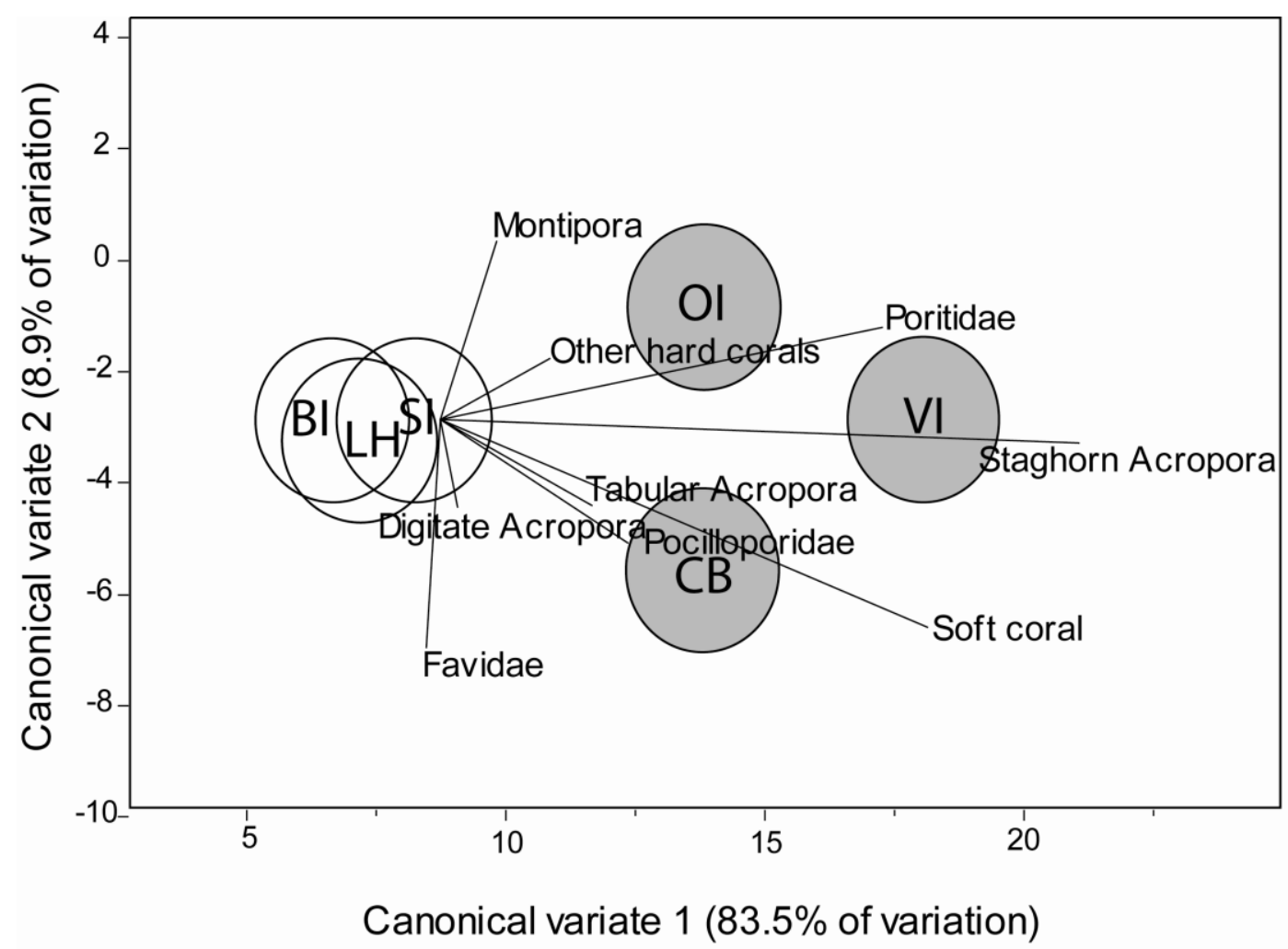

Figure 1 
A

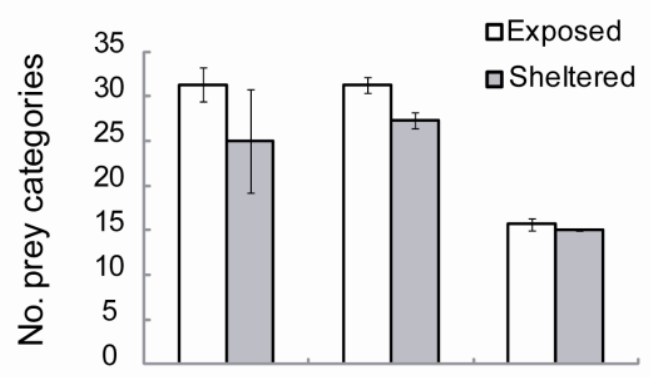

B

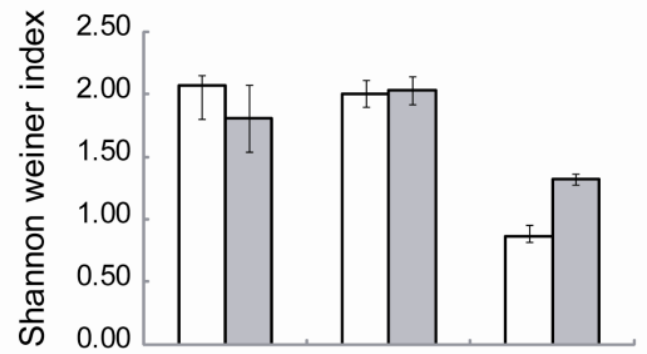

C

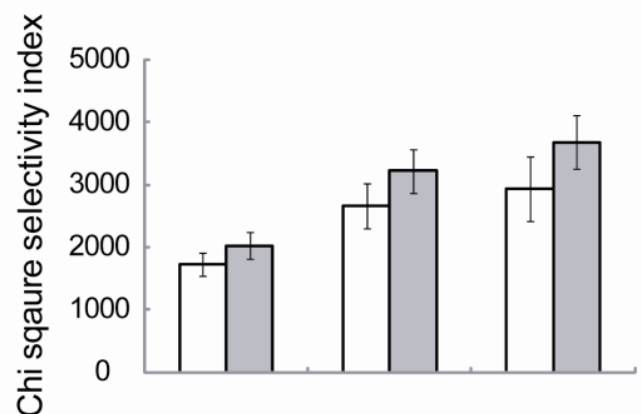

D

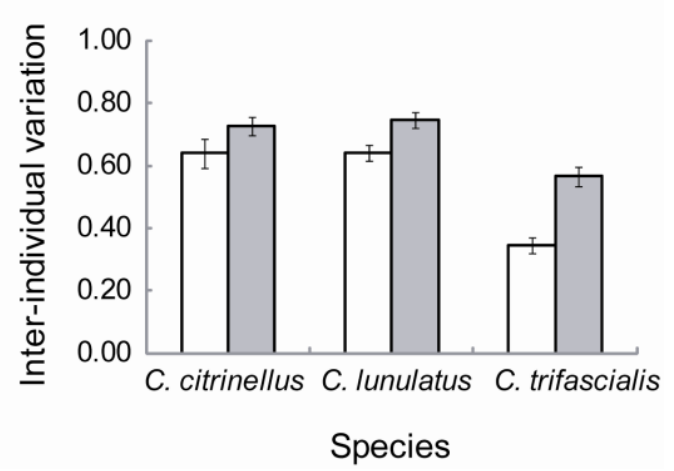

Figure 2 